BETELLA, Gabriela Kvacek. A intersecção dos planos de Nanni Moretti. Domínios da Imagem, Londrina, v. 12, n. 22, p. 5-21, jan./jun. 2018.

ISSN 2237-9126

Recebido em 29/9/2017 e aprovado em 30/11/2018

\title{
A INTERSECÇÃO DOS PLANOS DE NANNI MORETTI
}

\section{THE INTERSECTION OF SHOTS BY NANNI MORETTI}

Gabriela Kvacek Betella•

Resumo: O trabalho se enquadra numa pesquisa disposta a entender a visão da história contemporânea da Itália segundo enredos parcialmente autobiográficos, relacionados a uma problemática de grupo. Investigamos procedimentos cinematográficos que nos permitem afirmar que Nanni Moretti supera a mensagem política e revolucionária, pois sua mira transita entre passado e presente para interpretar de modo equilibrado o sentido político e a complexidade da crise coletiva e individual. A leitura considera as autoanálises dos protagonistas como reflexos das incoerências, acertos e heranças das forças de oposição difundidas desde os anos de 1960. A intenção é analisar o tratamento da "era Berlusconi" e a representação das contradições de um panorama social, um quadro político e um contexto cultural (sobretudo cinematográfico) preocupantes.

Palavras-chave: Nanni Moretti. Autobiografia. Il caimano.

\begin{abstract}
The work fits in with a research program willing to understand the vision of the contemporary history of Italy according to partially autobiographical storylines, linked to group-related issues. We investigate cinematographic procedures that allow us to affirm that Nanni Moretti overcomes the political and revolutionary message, for his sight moves between past and present in order to interpret in a balanced way the political meaning and the complexity of the collective and individual crisis. The Reading considers the self-analysis of the main characters as reflections of the incoherences, hits and inheritances of the opposition forces disseminated since the 1960's. Our aim is to analyze the treatment of the "Berlusconi Era" and the representation of the contradictions of a worrisome social landscape, political framework and cultural (mainly cinematographic) context.
\end{abstract}

Keywords: Nanni Moretti. Autobiography. Il caimano.

\footnotetext{
- Doutora em Teoria Literária e Literatura Comparada pela FFLCH-USP, com pós-doc no IEBUSP, docente no Departamento de Letras Modernas, área de italiano na Faculdade de Ciências e Letras da UNESP-Assis. Suas linhas de pesquisa se concentram atualmente sobre o cinema italiano contemporâneo.
} 
BETELLA, Gabriela Kvacek. A intersecção dos planos de Nanni Moretti. Domínios da Imagem, Londrina, v. 12, n. 22, p. 5-21, jan./jun. 2018.

ISSN 2237-9126

\section{Primeiro plano: a profundidade existencial}

Em raciocínio iluminador, Mariarosaria Fabris emprega uma expressão muito apropriada para descrever um dos contrastes da vida brasileira durante o regime militar, no início dos anos de 1970, quando a contracultura invadia o cenário nacional: vivíamos "a repressão sexual da direita e a intransigência puritana da esquerda" (FABRIS, 2014, p. 3). Repressão, de um lado, e intransigência, de outro, não só aproximam duas tendências políticas opostas, em consideração ao exagero e à imposição de papeis sociopolíticos, como o efeito das definições juntas é uma estranha democratização da perversidade, capaz de elucidar um eventual bloqueio de nossas opiniões ou opções políticas. Guardadas as proporções, é preciso ter um olhar analítico preciso como naquela expressão para interpretar de modo equilibrado os momentos (do passado ou do presente) em que parece não haver sentido político com bom senso. A dificuldade de exercício desse olhar reside na complexidade dos objetos coletivos, tão em crise quanto os sujeitos, dispostos a incorporar padrões que contradizem, creio, a nossa própria natureza. No Brasil, onde os partidos de esquerda passaram a ter atuação mais intensa após o regime militar, a intransigência (ou a transigência equivocada) da esquerda pouco foi discutida, como se constituísse um terreno intransponível ou uma prática usual para os próprios militantes. Esse tipo audacioso de análise, voltada para o contexto político italiano após os anos de 1970, é realizada pela obra do cineasta Nanni Moretti, cuja leitura parece oportuna para se pensar incoerências e acertos da herança das oposições aos regimes ditatoriais ou totalitários difundidas durante os anos de 1960.

As verdades profundas de ambientes privados e públicos contemporâneos, expressas em diversas formas artísticas, são melhor apresentadas quando se percebem suspensões, fraturas, disfarces, crises. De certo modo, o cinema de Nanni Moretti teve essa pretensão e também soube representar o presente com suas perdas por meio de uma crise radical 
BETELLA, Gabriela Kvacek. A intersecção dos planos de Nanni Moretti. Domínios da Imagem, Londrina, v. 12, n. 22, p. 5-21, jan./jun. 2018.

ISSN 2237-9126

do sujeito no mundo, crise que pode tomar as formas de neurose e de desorientação, com correspondências nas idiossincrasias (DE GAETANO, 2012 , p. 6). Em razão dessa plataforma, frequentemente vemos nos filmes do diretor o que a crítica tornou conhecido como drama cômico de uma subjetividade perdida nas formas inautênticas da vida social, com relação às quais não se sabe estar dentro nem permanecer fora, nem isolar-se, nem adequar-se (DE GAETANO, 2012, p. 10).

Quando Moretti lançava Ecce bombo (Nanni Moretti, 1978), Lino Micciché escrevia sobre a capacidade demonstrada pelo diretor de fazer cinema fora do cinema, isto é, de não industrializar o próprio talento, porém chamava a atenção, especialmente, para a continuidade estabelecida com o filme anterior, lo sono un autarchico (Nanni Moretti, 1976). Para Micciché (1978) o mesmo protagonista nos dois filmes (Michele Apicella), o mesmo problema existencial de uma geração inteira, o mesmo ambiente estudantil universitário, as mesmas formas de comunicação, a solidão coletiva, o sexo ao mesmo tempo disponível e impossível, são aspectos que se combinam à recusa de certos parâmetros, como o da biografia de uma geração, o da autobiografia individual e coletiva, e se completam com a comicidade calculada, sem apego ao moralismo ou às ideologias nas intenções. Na verdade, desde o seu primeiro filme, um curta rodado em Super-8 em 1973, essas marcas já eram evidentes'.

O que vale ressaltar do início da carreira cinematográfica de Moretti é a sua consciência de um tempo pós-68, da atuação da esquerda extraparlamentar (ou extrema-esquerda), dos debates que giravam em

\footnotetext{
1 Moretti, que se declara envolvido com a política de esquerda após 1968, realizou o curta La sconfitta em 1973 para falar da crise de um ex-militante de 1968. Pâté du bourgeois (Nanni Moretti, 1973) é o curta seguinte, cujo título faz um trocadilho com as expressões francesas "paté (de foie gras)" e "épater les bourgeois" ("impressionar os burgueses"), uma espécie de grito de guerra libertador dos poetas do final do século XIX, incluindo Baudelaire e Rimbaud. Moretti filma em seguida um média metragem com curiosa releitura de I promessi sposi (Os noivos), de Alessandro Manzoni, um clássico do romantismo literário italiano: Come parli frate? (Nanni Moretti, 1974) revisita o capítulo VI do romance de Manzoni dirigindo, pela boca do personagem Don Rodrigo (interpretado por Moretti), a pergunta do título ("Como falas, freie?") ao frei Cristoforo, que responderá: "Parlo come si parla a chi è abbandonato da Dio, e non può più far paura" ("Falo como se fala a quem foi abandonado por Deus, e não pode mais meter medo").
} 
BETELLA, Gabriela Kvacek. A intersecção dos planos de Nanni Moretti. Domínios da Imagem, Londrina, v. 12, n. 22, p. 5-21, jan./jun. 2018.

ISSN 2237-9126

torno da questão operária versus capital, bem como das contestações que tentavam desviar o foco desta e do perigo do desapego à memória das gerações anteriores ${ }^{2}$. Em seu segundo longa, Ecce bombo, Moretti faz aparecer, por meio de um grupo de jovens de esquerda, as contradições dos homens e mulheres envolvidos com uma argumentação no mínimo insustentável. A comicidade vem das situações patéticas cuidadosamente dosadas, resultando um procedimento capaz de refletir um estado de alma e situações de conflito geracional (MICCICHÉ, 1978, p. 295). No fundo, tais situações já refletiam um modo de se fazer política dos que se diziam, mas não diziam nada, que sabiam, mas não sabiam de si, que contavam de si, mas não se mostravam³.

Ambos os filmes captam o pequeno universo de jovens romanos, do norte da cidade, de Piazza Mazzini, jovens de formação de esquerda e voltados para a esquerda não-tradicional. Quando reafirma a capacidade de rir de si mesmo e de "dessacralizar" orientações teóricas e práticas políticas, Nanni Moretti refere-se sobretudo à sua formação e às suas dúvidas, manipuladas de modo a oferecer comicidade ao discurso.

A geração pós-68 e pós-revolucionária é vista pelas lentes de Moretti como praticamente inerte ou guiada por certas palavras de ordem que se tornam poderosas expressões de falta de empenho e da confusão penetrante nas convicções e práticas. Nem a satisfação pessoal genuína é garantida. A frase-chave de Ecce bombo sintetiza a alienação dos jovens

\footnotetext{
2 Na segunda metade dos anos de 1970, há uma espécie de refluxo nas ideias políticas, e o discurso de esquerda perde força e sentido. O terrorismo vai tomando formas assustadoras e isso passa a afetar os ideais e as relações intelectuais e, no que diz respeito ao cinema, remove-se das telas o discurso político e ideológico, mantendo as fugas por meio dos silêncios, do apelo ao erotismo, do mundo privado. Assim, as novas gerações de cineastas foram atingidas por esse refluxo ideológico, e foram privadas tanto de memória quanto de relações com os mitos sobre os quais os pais construíram a história dessa geração mais nova (BRUNETTA, 2004, p. 200).

3 A definição é elaborada pelo próprio diretor no documentário Qualcosa di sinistra (Wolfgang Achtner, 2007). É possível também ler a entrevista, em parte reproduzida do documentário, em GIANFRANCO (2002). Moretti explora o debate político tentando confrontar o absurdo da crise da centro-esquerda, a arrogância da centro-direita e o conflito de interesses do chefe do governo, pondo em xeque a classe política daquele momento, com base nos acontecimentos do passado recente - pelo menos dos anos de 1970 em diante e, em especial, dos resultados das eleições dos anos de 1990.
} 
BETELLA, Gabriela Kvacek. A intersecção dos planos de Nanni Moretti. Domínios da Imagem, Londrina, v. 12, n. 22, p. 5-21, jan./jun. 2018.

ISSN 2237-9126

aparentemente empenhados e parece girar em falso, improdutiva: "Passeio, vejo gente, me movimento, conheço, faço umas coisas". 4 A imprecisão característica de uma geração que não tem perspectivas é a tônica dos que não têm lado, opinião, em suma, são levados. O empenho não passa de um vazio intelectual, enquanto o ponto de vista parece ironizar essa postura. Assim, a expressão que se resumiu na cultura popular dos espectadores da época como "Giro, vedo gente, faccio cose" representa o vazio e a inatividade da jovem interpelada por Michele Apicella em Ecce bombo, mas o protagonista já se interrogava, em lo sono un autarchico, ao ler Marx:

As qualidades físicas da mercadoria, nas quais se deve cristalizar o estado de dinheiro de todas as mercadorias, ainda que derivem diretamente da natureza do valor de troca, são a divisibilidade a gosto, a uniformidade das partes e a identidade em todos os exemplares desta mercadoria. Como materialização... como materialização... Mas aqui não estou entendendo nada, talvez errei de ideologia? (apud BRUNETTA, 2004, p. 200, tradução nossa) ${ }^{5}$

Após criar e encarnar um padre incapaz de ajudar as pessoas mais próximas a si justamente quando reencontra suas origens completamente reviradas em La messa è finita (Nanni Moretti, 1985) e um deputado comunista, jogador de polo aquático (cujo lançamento preferido para surpreender o goleiro é a palombella) desmemoriado, para simbolizar um problema de memória da esquerda e de toda a sociedade italiana em Palombella rossa (1989), Moretti interpreta um membro da política italiana, corrupto e corruptor em I/ portaborse (Daniele Luchetti, 1991)6, aproveitando

\footnotetext{
4 "Giro, vedo gente, mi muovo, conosco, faccio delle cose"

5 Le qualità fisiche della merce particolare, nelle quali deve cristallizzarsi l'essere denaro di tutte le merci, perquanto derivino direttamente della natura del valore di scambio, sono la divisibilità a piacere, l'uniformità delle parti e la identità in tutti gli esemplare di questa merce. Come materializzazione... come materializzazione... Ma qui non sto capendo niente, forse ho sbagliato ideologia? (apud BRUNETTA, 2004, p. 200).

6 Moretti "sai do próprio eu", nas palavras de Gian Piero Brunetta (2004, p. 395), por interpretar o papel sem escrevê-lo. O crítico ainda argumenta que o comportamento do personagem concentra todos os vícios, ilegalidades, a arrogância, a corrupção, o senso de impunidade de uma classe política destinada a ser envolvida e apagada por uma onda de inquéritos e processos. No futuro, continua Brunetta, II portaborse poderá ser lido como documento real, quase como fonte primária da má administração pública e das razões que
} 
BETELLA, Gabriela Kvacek. A intersecção dos planos de Nanni Moretti. Domínios da Imagem, Londrina, v. 12, n. 22, p. 5-21, jan./jun. 2018.

ISSN 2237-9126

a imagem do seu personagem nos filmes anteriores, bastante familiar aos espectadores, para revelar durante a trajetória do ministro Cesare Botero a ausência de escrúpulos e a contrapartida amigável e bem construída na atividade do poder. Se o padre Don Giulio de La messa è finita resolve se refugiar na Patagônia diante de sua impotência, em contrapartida, o atleta Michele se esforça para encontrar uma solução positiva para seu drama, enquanto o ministro Botero exemplifica as nuances do discurso político contemporâneo, de um modo geral, muito bem sucedido.

Logo depois da queda do muro de Berlim, Moretti lança o documentário La cosa (Nanni Moretti, 1990), no qual dá voz a militantes do Partido Comunista Italiano, cuja direção propunha mudanças, inclusive no nome do partido. O filme mostra os debates em diversas sedes durante novembro e dezembro de 1989, e a preocupação com o futuro da esquerda. Com o documentário, o diretor correu muitos riscos, como o de assumir a crítica aos mecanismos da esquerda quando esta decidia não "lavar a roupa suja" em público - ou promover a "política da dupla verdade", no dizer de Moretti - e de ser instrumentalizado pela direita. No entanto, a capacidade de enfrentar esses riscos parece tirar as forças da motriz que prende in giro as convicções mais firmes, bem como o mundo existencial mais íntimo. Esse ângulo amplo passa a caracterizar os filmes dos anos de 1990, e a obra-chave é Caro diario (Nanni Moretti, 1993).

\section{Segundo plano: a autobiografia, a autoficção, a subjetividade}

Dividido em três episódios ("In Vespa", "Isole" e "Medici"), Caro diario (Nanni Moretti, 1993) se abre com a caligrafia miúda do "diarista", que escreve: "Caro diário, existe uma coisa que gosto de fazer mais que tudo"7. Moretti parece assumir uma definição pasoliniana segundo a qual a realidade pertence à dimensão oral (viva, extemporânea, mutável),

levaram grande parte da população a renegar toda uma classe política e a querer virar a página na própria história.

7 "Caro diario, c'è una cosa che mi piace fare più di tante!" 
BETELLA, Gabriela Kvacek. A intersecção dos planos de Nanni Moretti. Domínios da Imagem, Londrina, v. 12, n. 22, p. 5-21, jan./jun. 2018.

ISSN 2237-9126

enquanto o cinema é dimensão escrita (mumificada, programada, fixa), ou seja, o cinema para Moretti também é a "lingua escrita da realidade" (PASOLINI, 2010). O plano da frase é cortado e a Vespa percorre incansavelmente as ruas de bairros de Roma, sem o apelo aos clichês dos monumentos tão marcados em outros filmes como Roman Holiday (A princesa e o plebeu, William Wyler, 1953). A voz do protagonista é ouvida, para explicar $\circ$ gosto de ver as fachadas. A narrativa aproveita a convenção do tratamento familiar dos diaristas com o relato, o apego e a intimidade do adjetivo "caro" e reinventa o diário.

O protagonista percorre bairros muito populares, com alguma nostalgia e "tomando posse" de sua cidade, reconquistando o espaço atual. A cidade está vazia, provavelmente porque é verão. No interior do episódio, vários assuntos aparecem: a beleza paisagística e arquitetônica, as modificações e a decadência de alguns bairros, o cinema hollywoodiano, a crítica cinematográfica. De Garbatella a Ostia, o percurso recebe as confissões, entre as quais o desejo de aprender a dançar, entre outras reflexões sobre as próprias fraquezas e deficiências.

Caro diario é um filme muito bem-humorado, porém traz golpes certeiros, como o discurso sobre as maiorias e minorias em duas cenas: na primeira, a resposta a um filme que o protagonista assiste, no cinema vazio de Roma, com a cena de um grupo de pessoas concluindo que o tempo passou e ninguém melhorou, todos são cúmplices. O protagonista interrompe várias vezes a cena, dialoga com a projeção para exprimir sua indignação contra a fixação pelo "todos", e sua resposta aparece na narrativa elaborada no silêncio e na solidão do passeio na Vespa - se um dos personagens da cena diz que em seu passado todos gritavam coisas violentas, horrorosas, e ainda se enfearam, o protagonista repete a conclusão amarga e acrescenta: "(...) eu gritava coisas justas e agora sou um esplêndido quarentão" (trad. nossa),8 para que o espectador, imediatamente em seguida, se divirta com o efeito da canção incidental I'm

8 "(...) io gridavo cose giuste e ora sono uno splendido quarentenne" 
BETELLA, Gabriela Kvacek. A intersecção dos planos de Nanni Moretti. Domínios da Imagem, Londrina, v. 12, n. 22, p. 5-21, jan./jun. 2018.

ISSN 2237-9126

your man, de Leonard Cohen, e com a flagrante autoestima elevada do protagonista-diarista, matizada pela ironia provocada pela inserção da canção. Outro par de frases exemplar como subjetivação aparece na abrodagem de um homem em seu conversível, poderoso símbolo de status, quando o protagonista se dirige ao desconhecido: "Sabe o que eu estava pensando? (...) Eu acredito nas pessoas, porém não acredito na maioria das pessoas. Penso que ficarei sempre à vontade e de acordo com uma minoria" (trad. nossa). ${ }^{9}$ Assim como na cena anterior, o efeito de comicidade das falas espontâneas do protagonista encobre uma aguda crítica às maiorias, inclusive com desconforto por uma geração que se considera perdida.

Há confissões feitas para o diário deslocadas do narrador, ou seja, são observações voltadas para a crítica de comportamento, como a falta de preservação da memória, e de funções mal desempenhadas, como o papel do crítico de cinema. O protagonista lê para um crítico o texto que parece preencher o espaço impresso com considerações calculadamente elaboradas sobre Henry, pioggia di sangue (Henry, Portrait of a serial killer, John McNaughton, 1986). Como um fragmento de imaginação inserido em meio às reflexões do diarista que resolve transcrever em seu diário a crítica recém lida acerca de Henry, o protagonista se vê ao lado do crítico de cinema, no quarto, ao pé da cama, lendo o que parecem ser passagens de seus textos carregados de citações. O protagonista dispara as expressões cortantes, cuja força de sentido passa do efeito cômico à amarga constatação da superficialidade, do desserviço e do transtorno vindos da crítica nesse momento. Se o efeito vinha preparado desde as cenas exibidas de Henry, cuja violência não tem o conteúdo que o texto da resenha quer Ihe atribuir, o crítico desesperado, vítima de suas próprias frases, é o retrato da moderna rede que envolve as produções sem qualquer profundidade poética, representativa, reflexiva.

\footnotetext{
9 "Sai cosa stavo pensando? [...] lo credo nelle persone, però non credo nella maggioranza delle persone. Mi sà che mi troverò sempre a mio agio e d'accordo con una minoranza"
} 
BETELLA, Gabriela Kvacek. A intersecção dos planos de Nanni Moretti. Domínios da Imagem, Londrina, v. 12, n. 22, p. 5-21, jan./jun. 2018.

ISSN 2237-9126

No que diz respeito à memória coletiva, o plano-sequência filmado em Ostia fecha o primeiro episódio e nos oferece as dimensões possíveis num único plano. The Köln Concert de Keith Jarrett começa a ser ouvida ao mesmo tempo em que vemos jornais folheados e uma coleção de recortes trazendo como assunto a morte de Pasolini, em novembro de 1975. A música começa exatamente no plano que corta a sequência anterior, do implacável diarista a fuzilar o crítico de cinema com suas próprias frases sem sentido.

O silencioso percurso, ao som exclusivo da música de Jarrett, segue a via dell'Idroscalo nos dois sentidos, até concluir-se em frente ao monumento degradado, em terreno abandonado. A cena traz uma direta referência ao cineasta bolonhês, é uma homenagem conforme a crítica constata, porém, segundo Mariarosaria Fabris, "(...) Moretti demonstrava ter compreendido o ensaio 'Cinema de poesia', de 1965, em que Pasolini afirma que a vida se reproduz no plano-sequência, cujo significado é dado pelo corte que interrompe o fluxo contínuo de imagens, assim como a morte dá um sentido à trajetória humana." (FABRIS, 2008, p. 98-99) Quando Pasolini (2010) elaborou o conceito de subjetiva indireta livre para traduzir para a linguagem cinematográfica a utilização do discurso indireto livre no cinema, talvez não soubesse como facilitaria o emprego de termos adequados e a visualização de certos procedimentos nos filmes pelos estudiosos de literatura. Assim, ao afirmar que o plano sequência pode ser considerado a mais intensa manifestação da subjetividade com intenções objetivas, Pasolini considerava a sobreposição de intenções objetivas e subjetivas, efeito conseguido pela referida sequência em Caro diario.

O plano que antecede a silenciosa decepção com a memória de Pasolini intensifica a ação sem palavras que atira para o espectador uma espécie de alegoria do contemporâneo com a delícia e a desgraça da relação com o passado. Contudo, Gian Piero Brunetta (2004) afirmou que as deambulações do personagem levam-no a uma nova percepção do eu, a uma diferente capacidade de medir o mundo e de medir-se em relação ao 
BETELLA, Gabriela Kvacek. A intersecção dos planos de Nanni Moretti. Domínios da Imagem, Londrina, v. 12, n. 22, p. 5-21, jan./jun. 2018.

ISSN 2237-9126

mundo. Entendemos, assim, que Moretti desenvolve uma percepção de seu tempo e espaço sem sentimentalismos, criando uma medida de atualidade, que se afirma com as relações estabelecidas no seu próprio processo criativo, filme a filme.

Nos episódios seguintes, Caro diario ressalta pontualmente a figura do protagonista às voltas com suas anotações, ora para o registro íntimo, ora para angariar material para um filme - esta situação, aliás, é recorrente nos longas de Moretti em que o personagem interpretado pelo diretor é um cineasta. As observações pessoais se misturam às conclusões em tom menos carregado que no primeiro episódio. Embora o trabalho de pesquisa seja levado a sério, situações cômicas que transformam o perfil contestador do personagem numa figura meio trickster, meio stand up comedy, figuras que poderiam se assemelhar, no caso das performances de Nanni Moretti, a Antoine Doinel de Truffaut.

Em "Isole" o protagonista segue para a ilha de Lipari e questiona seus métodos de composição criativa. Encontrar o amigo Gerardo, estudioso de James Joyce, que não vê televisão há 30 anos, mas termina o episódio louco de curiosidade para saber o desfecho de um programa televisivo. 0 desempenho desse personagem nos faz pensar na impossibilidade de se racionalizar um combate à cultura de massa por meio de regras de comportamento douto que incluem o afastamento dos objetos de consumo. A visita às ilhas revela índices de degradação material e moral: o espaço antes retratado por Roberto Rossellini e Michelangelo Antonioni é destituído ao turismo de massa (FABRIS, 2008), com algumas idiossincrasias morettianas elevadas a superação.

O terceiro episódio retrata um episódio autobiográfico autêntico, a experiência dos sintomas, do complicado diagnóstico e da cura de um linfoma de Hodgkin. A estrutura faz uso do flashback, a partir do protagonista escrevendo em seu diário, cercado de receitas médicas e medicamentos. No corte, a cena seguinte é trazida de uma tomada de $16 \mathrm{~mm}$ da última sessão de quimioterapia. O episódio prossegue, sempre em retrospectiva, 
BETELLA, Gabriela Kvacek. A intersecção dos planos de Nanni Moretti. Domínios da Imagem, Londrina, v. 12, n. 22, p. 5-21, jan./jun. 2018.

ISSN 2237-9126

com a encenação do longo percurso de especialistas até o diagnóstico definitivo. A montagem evidencia a aparente segurança dos médicos e a ineficácia de cada tratamento, com o sintoma principal (uma coceira intensa) piorando, em efeito cômico, reforçado pela filmagem limpa, essencialmente com enquadramentos fixos. De volta ao cenário inicial (uma cafeteria), o protagonista pede o café da manhã e um copo de água. No último quadro, após afirmar que a única ideia em concordância com todos os tratamentos é o copo de água matinal, ele olha para a câmera, como a estabelecer uma nova direção do discurso, incluindo um novo sujeito.

Caro diario termina sem medo de incluir parâmetros literários no discurso cinematográfico, ainda que destacá-los seja um risco, na medida em que o sujeito que narra o filme nem sempre corresponde ao narrado e, com isso, a narrativa fílmica permite a existência de mais de um sujeito na mesma cena. Três ou mais dimensões do espaço podem corresponder a pontos de vista subjetivos e diferentes: a voz em off, a câmera e o protagonista enquadrado.

\section{Plano e contraplano: o efeito Moretti}

Und der Haifisch, der hat Zähne Und die trägt er im Gesicht Und Macheath, der hat ein Messer Doch das Messer sieht man nicht. Bertolt Brecht, Die Moritat von Mackie Messer

Para contar a aventura política que incluiu o nascimento do partido Forza Italia e parte da trajetória de Silvio Berlusconi, Moretti encontrou o tom que Ihe pareceu justo em Aprile (Nanni Moretti, 1998), fixando determinadas imagens do período compreendido entre a eleição de 1994 e a de $1996^{10}$ e tido por Peter Bondanella como a sequência lógica de Palombella rossa

10 As eleições italianas de 1994 renovavam o Parlamento, e aconteceram em 27 e 28 de março de 1994. Pela primeira vez na República Italiana, houve eleições após dois anos do pleito anterior. Em 21 de abril de 1996 ocorre pela segunda vez uma eleição antecipada. Em consequência, num espaço de quatro anos, pela primeira vez na história, houve três eleições. Em 1994 e 1996, os quadros eram bem diferentes, conforme veremos ao longo do trabalho. 
BETELLA, Gabriela Kvacek. A intersecção dos planos de Nanni Moretti. Domínios da Imagem, Londrina, v. 12, n. 22, p. 5-21, jan./jun. 2018.

ISSN 2237-9126

(Nanni Moretti, 1989) e como antecipação de Il caimano (Nanni Moretti, 2006). Assim, no calor daquele final de década, Moretti avalia o surgimento e o estabelecimento de um partido de centro-direita no poder, seguido de sua derrota pela centro-esquerda, cuja coalizão venceu em nove regiões contra seis da centro-direita - o que pode ser visto também na década seguinte, quando Berlusconi perde as eleições gerais para voltar ao poder como primeiro-ministro em 2008. Novamente, veem-se entrelaçados a política, o embate do cineasta (que precisa decidir se fará um filme contemplando a memória histórica ou um musical) e um aspecto importante da vida pessoal - a paternidade. Todas as instâncias são tratadas a partir de suas idiossincrasias.

Os anos de 1990 trouxeram redefinições obrigatórias tanto para as forças de esquerda quanto para as tendências moderadas. Isso porque no início da década uma grave crise política se intala devido ao escândalo da corrupção na política, seguida pela instauração das chamadas Mani pulite (Mãos limpas) ${ }^{11}$. Uma nova lei eleitoral é adotada, há muita migração de membros de partidos políticos. O cenário fica definido basicamente com os novos partidos PDS (Partito Democratico della Sinistra, derivado do PCl); o PPI (Partito Popolare Italiano, vindo da Democrazia Cristiana); Forza Italia, cuja figura central era Silvio Berlusconi, e Aleanza Nazionale, com diversos estratos políticos, especialmente o MSI (Movimento Sociale Italiano).

Segundo Paolo Flores D'Arcais (2011 , p. 62), o partido Forza Italia surge a partir de uma negociação do Estado com organizações mafiosas e empresas de publicidade, embora judicialmente ainda haja falta de provas. Além disso, haveria uma ligação do partido com o assassinato de Paolo Borsellino ${ }^{12}$. Pelo menos desde o "biênio decisivo" de 1992 (assassinatos dos

\footnotetext{
11 A expressão é atribuída a Giorgio Amendola, membro do PCl (Partito Comunista Italiano), que a teria utilizado numa entrevista. Mani pulite designou algumas operações contra a corrupção e também especificou ações restritas a certas regiões, mas logo passou a se referir a todas as atividades do judiciário no combate à corrupção.

12 Paolo Borsellino (1940-1992) e Giovanni Falcone (1939-1992) foram magistrados de grande papel no sentido de darem prosseguimento aos processos contra a máfia no sul da Itália, dentro da operação Mãos limpas. Ambos foram assassinados com poucos meses de diferença entre os atentados.
} 
BETELLA, Gabriela Kvacek. A intersecção dos planos de Nanni Moretti. Domínios da Imagem, Londrina, v. 12, n. 22, p. 5-21, jan./jun. 2018.

ISSN 2237-9126

magistrados Falcone e Borsellino) e 1993 (atentados ao patrimônio artístico de Roma e ao Estadio Olimpico de Florença) a Itália viveu uma "contrafação da democracia", com a controvérsia política perdendo a ligação com a argumentação racional. Para D' Arcais:

Não existem mais os "fatos", mas ninguém tampouco se prende aos vínculos da lógica. Pode-se desmentir hoje o que foi afirmado ontem; no mesmo programa de entrevistas, podese sustentar uma opinião e o contrario dela, uma opinião e o oposto das consequências logicamente derivadas dela. O que importa e a capacidade de berrar interrompendo 0 adversário, o histrionismo da atitude, o descaramento em mentir, a arrogância da "bela figura" e a vulgaridade do insulto colocado no momento certo. Torna-se "virtude" toda a panóplia das falácias semânticas e pragmáticas estigmatizadas nos tratados de retórica.

O não raciocínio se torna uma segunda natureza para o político, mas também para o eleitor. Este, aliás, no desprezo do político pelos fatos e pela lógica, sofre o fascínio da "vontade de poder". Desprezo que, aclamado em vez de desmascarado, se traduz em "delírio de onipotência" para o político, em volúpia de submissão para o ex-cidadão. (D'ARCAIS, 2011, p. 64)

Nanni Moretti dirige seu olhar para a política italiana com rigor. Aprile se inicia com o anúncio da vitória de Berlusconi nas eleições de 1994. O protagonista, Nanni Moretti, assiste ao telejornal e, entre a sensação desconcertante e a vontade de agir, pensa em realizar um documentário sobre a figura de Berlusconi e o conflito de interesses. Contudo, o projeto cede lugar a um musical, que revive a atmosfera do auge desse gênero e parece encobrir a situação política com o colorido do filme dentro do filme. O projeto é suspenso por falta de ideias, e chega a época das eleições antecipadas de 1996. Moretti volta a pensar no documentário político, quando descobre que será pai.

O filme repassa a vida cotidiana do diretor, em suas atividades de trabalho e os cuidados com o filho. As duas instâncias trazem dificuldades. $\bigcirc$ documentário não fica pronto, o projeto é abandonado novamente e o musical volta a ser produzido, sob a atmosfera da vitória da esquerda nas 
BETELLA, Gabriela Kvacek. A intersecção dos planos de Nanni Moretti. Domínios da Imagem, Londrina, v. 12, n. 22, p. 5-21, jan./jun. 2018.

ISSN 2237-9126

eleições de 1996. Há aqui um aparente paradoxo, pois o documentário engajado parecia fazer sentido para o diretor somente quando as expectativas foram frustradas pela derrota da esquerda por Berlusconi. Se levamos em conta o famoso fragmento borgiano, também nos lembramos da relação entre o trabalho intelectual e as certezas:

Em tempos de apogeu a conjectura de que a existência do homem é uma grandeza constante, invariável, pode ser causa de tristeza ou de irritação; em tempos de declínio (como estes), é a de que nenhum opróbio, nenhuma calamidade, nenhum ditador poderá nos empobrecer. (BORGES, 2016, p. 76)

Podemos considerar que o cineasta estaria vivendo tempos de declínio, então o documentário é motivado pela vontade de resistir. No entanto, a motivação do musical permanece em tempos de apogeu e de declínio, como a convencer o realizador de que não há grandezas constantes na existência capazes de ultrapassar o sentido necessário com certa alienação para suportar a calamidade que, por sua vez, não é repentina.

Em 1996, as eleições definiram um sistema bipolarizado, e muitos novos partidos apareceram. Os centristas de 1994 se reuniram no Partito per l'Italia, que se dividiu entre o Partito Popolare Italiano (centro-esquerda) e os Cristiani Democratici (centro-direita). Havia ainda o Patto Segni, integrado à Lista Dini: Rinnovamento Italiano.

As relações entre os filmes Aprile e II Caimano passam por II portaborse (Daniele Luchetti, 1991), em que a discussão sobre corrupção na política italiana é colocada, com Moretti na interpretação de um ministro numa trama ficcional. A mistura de gêneros, por outro lado, angaria mais recursos expressivos para contar o presente. Assim, II Caimano dirige a atenção do espectador para a trama principal, protagonizada pelo produtor cinematográfico em crise Bruno Bonomo, cuja esperança de retomada na carreira é o roteiro de uma jovem cineasta, Teresa. O filme II Caimano seria a 
BETELLA, Gabriela Kvacek. A intersecção dos planos de Nanni Moretti. Domínios da Imagem, Londrina, v. 12, n. 22, p. 5-21, jan./jun. 2018.

ISSN 2237-9126

história de Silvio Berlusconi, pela qual Bonomo se interessa, mas as filmagens encontram muitos obstáculos.

Se a ascensão de Berlusconi pode ser vista como "uma forma nova e inédita de destruição das instituições liberal-democráticas e do ethos público mínimo que as sustenta" (D'ARCAIS, 2011, p. 64), sua permanência no poder provocou estragos profundos, muito pelo fato de se conceber o Estado como mundo empresarial. Análises competentes visualizaram desde as primeiras manifestações semelhantes a um regime totalitário (e, portanto, é inevitável não estabelecer uma ligação com o fascismol até as possibilidades de destruição da democracia por formas inéditas de manipulação, ainda que a Europa (e o resto do mundo) prefira ver Berlusconi como um personagem farsesco. É oportuno lembrar que o personagem esteve no poder e, portanto, uma farsa nessa esfera pode significar um grande estrago nas instituições. Em /l Caimano, essa dimensão é lembrada de forma incisiva. O ator Elio De Capitani vive o político "real" no filme de Moretti, como uma das formas possíveis de se representar o passado imediato. A proximidade física do ator sugere uma nota de falsidade, de caricatura mórbida, de sombra deformada.

Enquanto Bonomo tenta rodar seu filme, a relação com a esposa se deteriora. Embora o esforço tenha sido grande, o realizador consegue filmar somente as últimas cenas, centrais para a interpretação do sentido que o filme dentro do filme pode oferecer à obra de Moretti. As cenas recuperam e dão sentido à artificialidade das aparições de Berlusconi interpretado por De Capitani. No filme de Bonomo, Berlusconi, interpretado por Nanni Moretti, está vulnerável, em pleno final do processo ${ }^{13}$ no qual seria condenado a sete anos. Ainda assim, sua saída do tribunal é cercada por um tom ameaçador da parte do político, que deixa o prédio aclamado por uma pequena multidão, que se volta violentamente contra o júri, que deixa o prédio em seguida. A imagem de Berlusconi sentado no carro, com o rosto no escuro e a luz das explosões dos coquetéis molotov ao fundo deixa a impressão de

13 Possivelmente o filme se refere ao processo SME, em que se investigou a compra irregular de empresas alimentícias, em que estavam envolvidos Silvio Berlusconi e Cesare Previti. 
BETELLA, Gabriela Kvacek. A intersecção dos planos de Nanni Moretti. Domínios da Imagem, Londrina, v. 12, n. 22, p. 5-21, jan./jun. 2018.

ISSN 2237-9126

que as ameaças já estão se cumprindo. Moretti exagera no artifício que culmina com a sua própria interpretação, problematizadora de todas as relações expostas no filme.

\section{Referências}

AGAMBEN, Giorgio. O autor como gesto. In: Selvino J. Assmann. São Paulo: Boitempo, 2007. p. $\overline{55-63 .}$

Profanações. Trad.

APRILE. Direção: Nanni Moretti. Itália: 1998. (78 min).

BONDANELLA, Peter. Italian cinema. In: BARANSKI, Z. G. e WEST, R. J. The Cambridge companion to modern italian culture. Cambridge: Cambridge University Press, 2001, p. 215-242.

BORGES, Jorge Luis. O tempo circular. In: História da eternidade. Trad. Heloisa Jahn. São Paulo: Companhia das Letras, 2010.

BRUNETTA, Gian Piero. Cent'anni di cinema italiano. Vol. 2: Dal 1945 ai nostri giorni.

BRUNETTA, Gian Piero. Cent'anni di cinema italiano. Vol. 2: Dal 1945 ai nostri giorni.

CARO DIARIO. Direção: Nanni Moretti. Itália: 1993 (96 min).

D'ARCAIS, Paolo Flores. Fascismo e Berlusconismo. Novos Estudos, n. 91 , p. 5473, 2011.

DE GAETANO, Roberto. Nanni Moretti: Lo smarrimento del presente. Cosenza: Pellegrini, 2012.

FABRIS, Mariarosaria. Anos de sonho e de sangue. In: KUSHNIR, Beatriz et al. (org.). Anais do XVI Encontro Regional de História da ANPUH-Rio - Saberes e práticas científicas. Rio de Janeiro: ANPUH-Rio, 2014, p. 1-14. Disponível em http://www.encontro2014.rj.anpuh.org/resources/anais/28/1400289817_ARQU IVO_MariarosariaFabris.pdf, acessado em 15.03.2017.

FABRIS, Mariarosaria. O cinema italiano contemporâneo. In: BAPTISTA, Mauro e MASCARELLO, Fernando. (org.). Cinema mundial contemporâneo. Campinas: Papirus, 2008, p. 91-106.

GENETTE, Gérard. Fiction et diction. Paris: Sevil, 1991. 
BETELLA, Gabriela Kvacek. A intersecção dos planos de Nanni Moretti. Domínios da Imagem, Londrina, v. 12, n. 22, p. 5-21, jan./jun. 2018.

GIANFRANCO, Mascia. Qualcosa di sinistra. Genova: Frilli, 2002.

GILI, Jean. A. Nanni Moretti. Roma: Gremese, 2006.

IL CAIMANO. Direção: Nanni Moretti. Itália: 2006. (112 min).

IL PORTABORSE. Direção: Daniele Luchetti. Itália: (92 min).

KLINGER, Diana. Escritas de si, escritas do outro: o retorno do autor e a virada etnográfica. 3. ed. Rio de Janeiro: 7 Letras, 2012.

MICCICHÉ, Lino. "Ecce bombo" di Nanni Moretti. In: Cinema italiano degli anni '70. 2. ed. Venezia: Marsilio, 1989, p. 294-295.

PASOLINI, Pier Paolo. Empirismo eretico. 3. ed. Milano: Garzanti, 2010.

QUALCOSA DI SINISTRA. Direção Wolfgang Achtner. Itália: 2007 (52 min). 